\title{
Preschool girls' distress and mothers' sensitivity in Japan and Germany
}

\author{
Gisela Trommsdorff \\ University of Konstanz, Konstanz, Germany \\ Wolfgang Friedlmeier \\ Grand Valley State University, Allendale, MI, USA
}

\begin{abstract}
Cultures differ in their beliefs about emotions and related emotional expressions. Cultures with an interdependent model of self prefer more socially engaged emotions, and cultures with an independent model of self perceive socially disengaged emotions as more important. Such differences in individual emotional expression can be seen as outcomes of different socialization practices in children's development of emotions. Mothers' sensitivity was assumed to promote culturally valued ways of children's emotional expressions. The present cross-cultural study aimed to test distress reactions of young children in Japan and Germany in self-focused and otherfocused conditions. German and Japanese preschool girls $(N=50)$ were observed in two distress conditions. Distress was evoked by the child's own failure (self-focused distress) and by the experience of another person's distress (other-focused distress). The mothers were present in the failure condition. The girls' intensity of distress expression was coded before and directly after the emotion-eliciting event (immediate expression) as well as at the end of each situation (change of expression over time). Mothers' sensitivity was coded during the failure condition. No cultural differences occurred for girls' intensity of immediate distress expression but for the change of expression over time in both situations in the expected culture-specific way. Furthermore, maternal sensitivity was also related to the daughter's change of distress expressions in a culture-specific
\end{abstract}

Correspondence should be addressed to Gisela Trommsdorff, University of Konstanz, Dept. of Psychology, Box D14, 78457 Konstanz, Germany.

E-mail: gisela.trommsdorff@uni-konstanz.de

This study was supported by grants from the German National Science Foundation (Deutsche Forschungsgemeinschaft, DFG, AZ: Tr 169/4-3; GZ: Tr 169/14-2) and the Japan Foundation to Gisela Trommsdorff.

We thank Makoto Kobayashi for collecting the data in Japan and helping to organize the coding of the observations. We are very grateful to Fred Rothbaum and Holly Bunje for their valuable comments and suggestions on an earlier version of this manuscript.

(C) 2009 Psychology Press, an imprint of the Taylor \& Francis Group, an Informa business http://www.psypress.com/edp

DOI: $10.1080 / 17405620802252742$ 
way. These results point to effects of universal and culture-specific emotion socialization.

Keywords: Culture; Development; Distress; Emotion; Preschoolers; Sensitivity.

Several studies have reported evidence for cultural differences in the elicitation, expression, labelling, and management of emotions (e.g., Friedlmeier \& Matsumoto, 2007; Mesquita \& Frijda, 1992). The socialization of emotions is influenced by cultural meaning systems for the expression and regulation of emotions (e.g., Trommsdorff \& Rothbaum, 2008). Accordingly, children learn to display and regulate their emotions in order to adapt to socio-cultural expectations regarding situation-specific appropriate emotional functioning (e.g., Eisenberg, Cumberland, \& Spinrad, 1998; Holodynski \& Friedlmeier, 2006; Raver, 2004). The display of emotions is based on emotion knowledge and the ability of emotion regulation as part of emotional competence (Saarni, 1998). The empirical evidence of cultural differences in children's emotional expression and related socialization practices is still limited (e.g., Cole, Tamang, \& Shrestha, 2006). Furthermore, there is still a lack of knowledge about whether these culture-specific practices affect the spontaneous display of emotion or rather the maintenance/change of an expression after its occurrence.

The main goal of this study was to test the impact of culture and culturespecific socialization conditions on children's negative emotional expression (distress) by analysing spontaneous distress reactions as well as the maintenance of the distress reaction over a short time (2 minutes). Japanese and German preschool girls' emotional expressions ${ }^{1}$ were observed in two experimentally controlled situations. Mothers' reactions to their daughters' emotional displays were assessed in one situation. Japan and Germany were chosen in particular because they represent different cultural contexts with different models of emotion.

\section{Culture and emotional development}

The expression of emotions is influenced by the cultural model of the self, which moderates the meaning of emotion-eliciting situations (Kitayama \& Markus, 1994). Therefore, it is useful to compare the

\footnotetext{
${ }^{1}$ Some empirical studies have shown gender differences in emotion socialization and children's emotional reactions (Chaplin, Cole, \& Zahn-Waxler, 2005; Fivush, 1998). We decided not to study gender differences but to stay with a gender-homogenous sample. Given a reduced small sample size due to multiple sessions, we selected only girls as participants in order not to loose further statistical power for testing the hypotheses with respect to gender-specific effects.
} 
expression of children's emotions in cultural contexts that represent the model of interdependence and the model of independence. These two models are not sufficient to describe the complexity of cultures and the related socialization practices. However, in order to improve our understanding of the underlying developmental processes for cultural differences and similarities in the expression of emotions, it seems reasonable to compare children from cultural contexts that represent different, theoretically relevant, developmental pathways (Greenfield, Keller, Fuligni, \& Maynard, 2003).

Societies characterized by highly interwoven social relations based on the cultural model of "interdependence" emphasize socially engaged emotions (Kitayama, 2001) that refer to positive or negative emotions focusing on others, e.g., shame or empathy. The expression of other-focused distress can be regarded as a form of socially engaged emotion, which is more valued in cultures favouring the model of interdependence compared to cultures favouring the model of independence. In contrast, the expression of distress caused by one's own situation and focusing on one's personal disappointment (self-focused distress) can be regarded as a form of socially disengaged emotion. Socially disengaged emotions refer to emotions caused by one's own situation and focusing on the self, e.g., happiness, frustration, or anger. In societies valuing the cultural model of "independence", the expression of self-focused distress is likely to be more acceptable compared to otherfocused distress. This perspective is in line with Zahn-Waxler, Friedman, Cole, Mizuta, and Hiruma (1996) who differentiate between the otherdirectedness of Japanese and the self-directedness of US children's emotional reactions (see Trommsdorff, 2006; Trommsdorff \& Rothbaum, 2008).

The comparison of children's expression of distress in different situations is based on the assumption that the cultural model of the self affects the socialization practices that influence the development of children's emotional expression. In a cultural context where values of interdependence prevail, children learn to refrain from expressing their own distress in order to maintain harmonious interpersonal relations (Azuma, 1986) and otherfocused distress fits with the value of concern for others. Accordingly, we assume that the expression of other-focused distress is encouraged, whereas the expression of self-focused distress is rather discouraged. In contrast, in a context where values of independence prevail, the expression of any kind of emotions is more strongly encouraged, based on the individualistic belief that the expression of one's emotions fosters open interpersonal communication. Therefore, children's expression of negative emotions regarding their own failure (self-focused distress) can be assumed to be less discouraged and more accepted as an appropriate behaviour indicating authentic expression of emotions. The expression of other-focused distress is 
accepted if understood as an authentic expression of empathy and relatedness (Rothbaum \& Trommsdorff, 2007), but not emphasized as strongly as in cultures favouring interdependence.

The cultural contexts selected here represent one Western and one East Asian culture: Germany is rather characterized by the cultural model of independence and Japan by the cultural model of interdependence. Even though Japan and Germany share similarities in socioeconomic development before and after the Second World War, their cultures provide different socialization contexts for children. The developmental path of Japanese children can be characterized by symbiotic harmony and interdependence while for German children it has been characterized by individual autonomy, interpersonal negotiation, and independence (Rothbaum, Pott, Azuma, Miyake, \& Weisz, 2000). This dichotomy serves as a heuristic framework to derive hypotheses on culture-specific differences, while intracultural variations have to be taken into account (e.g., Heine, 2001; Markus \& Kitayama, 1991; Rothbaum \& Trommsdorff, 2007).

\section{Culture-specific socialization of emotions}

Development of experience and expression of emotions is influenced by multiple conditions, including factors from within and outside of families, e.g., parents, siblings, peers, and multiple influences from the wider socio-cultural context (Cole \& Tan, 2006; Rothbaum \& Trommsdorff, 2007). Here, we focus on the mother as an important socialization agent.

In Japan, mother-child relationships are characterized by close emotional bonding that includes strong child-focused attention of mothers (Caudill \& Weinstein, 1986; Lebra, 1994; Trommsdorff \& Friedlmeier, 1993) as well as "amae" - a feeling of mutual dependence (Doi, 1973; Yamaguchi \& Ariizumi, 2006). This specific quality of mother-child relation in Japan has been described as a symbiotic relationship based on the feeling of oneness (ittaikan; Azuma, 1986; Lebra, 1994; Rothbaum \& Morelli, 2005), which may strengthen children's other-focused concerns.

Furthermore, the ability to accommodate own needs to situational demands and to regulate the expression of emotions accordingly is an important developmental task for Japanese children (e.g., Trommsdorff \& Rothbaum, 2008). Emotion regulation is an important task in all cultures, however, in Japan, the ability to "control" the expression of one's emotion, especially self-focused emotions, is highly valued and seen as an indicator for maturity (Lebra, 1994). The long period of indulgence until enrolment in school may provide less experience with self-focused distress for Japanese children and is in line with a generalized cultural belief that 
potentially frustrating situations will not turn out harmful either for oneself or for other persons. This cultural context of assurance can be seen as a basis to perceive potentially frustrating situations as less harmful and thus may reduce the expression of self-focused distress (Trommsdorff \& Rothbaum, 2008).

During their development, Japanese children experience the rewards of interdependence, the malleability of the self, and the value of social harmony. The expression of other-focused distress would indicate successful development of concern for others, a highly valued aspect of interdependence. To conclude, the developmental path of Japanese children is based on the cultural norm to avoid the expression of self-focused negative emotions, while the expression of other-focused emotions is not discouraged.

In contrast, in Germany, children's early experience of an independent self provides the basis for re-occurring frustrations and the need for selfassertion. Also, German children are more often confronted with other person's expressive emotional reactions including self-focused negative emotions (such as anger). This experience may reinforce the learning to openly express self-focused distress. Therefore, we expect that German as compared to Japanese children will express more self-focused distress.

The experience of concern for others is also a relevant socialization goal in Western countries (Trommsdorff, Friedlmeier, \& Mayer, 2007). Young German children may therefore express distress when confronted with negative emotional reactions of others. However, the emphasis of other-focused distress is not as strong as in Japan. Therefore, it is expected that German children express self-focused distress less than Japanese children.

These different cultural patterns of socialization of emotions described above are assumed to influence the spontaneous expression of emotion as well as the maintenance of expression over time in distress-evoking situations. Culturally valued emotional expressions may be displayed more strongly (immediately after the causing event) and sustained for a longer time. In contrast, culturally less valued emotional expressions may be expressed less and only for a short period of time.

The socialization of emotions may vary for boys and girls within each culture, and according to the developmental age. So far it is unknown how the gender-specific socialization practices vary across different periods of childhood. The results of studies for preschoolers in Western cultures are inconsistent. For example, Eisenberg, Fabes, and Murphy (1996) reported differences, whereas Kliewer, Fearnow, and Miller (1996) failed to document parental gender-differentiated responses to children's emotional reactions. Gender-specific socialization processes seem to be subtle for the preschool period, at least in Western culture (Fivush, 1998). Here, we only tested mothers and their daughters (see also Footnote 1). 
By assuming that the above described cultural specifics regarding beliefs on the expression of emotions and related socialization practices apply for mothers and their daughters, we derived four hypotheses regarding the strength of spontaneous expression and its maintenance/ change of expression over time when experiencing self- or other-focused distress:

1. German preschool girls display a stronger expression of self-focused distress than Japanese preschool girls.

2. German preschool girls sustain their expression of self-focused distress more strongly compared to Japanese preschool girls.

3. Japanese preschool girls display a stronger expression of otherfocused distress than German preschool girls.

4. Japanese preschool girls sustain their expression of other-focused distress more strongly compared to German preschool girls.

\section{Mothers' sensitivity}

Maternal sensitivity is indicated by comforting and helping; it implies responding to the child's needs with behaviours appropriate to the situation and the child's signals. Maternal sensitivity is influenced by the child and also by the social and cultural context in which it occurs and can be conceived of as an indicator of the quality of the mother-child relationship (Fogel, 1993). Both the signals of the child and the responses of the mother are part of the dyadic relationship embedded in the given cultural context. Mothers' sensitivity to children's distress is related to children's emotional development (Kochanska, 2001). According to attachment theory, children's early experience with sensitive caregivers provides the basis for secure attachment and the development of an "internal working model", which, in turn, allows for successful self- and emotion regulation (Bowlby, 1982; Bretherton, Golby, \& Cho, 1997).

Maternal sensitivity to distress facilitates children's internalization of cultural values and mothers' expectations about adequate emotional expression (e.g., Grusec \& Davidov, 2007). Mothers' expectations of their children's adequate emotional expression are presumably informed by the prevailing cultural model. Therefore, we assume that children of highsensitive mothers will display the kind of emotional expression (spontaneous and maintained/changed expression over time) that is preferred in the respective culture. Accordingly, we derive the following further hypothesis:

5. Cultural differences in girls' expression of distress will be more pronounced in dyads with high-sensitive compared to dyads with lowsensitive mothers. 


\section{METHOD}

\section{Participants}

These were 20 Japanese and 30 German 5-year-old preschool girls and their respective mothers. The children were recruited from private and public middle-class kindergartens in Fujisawa, a suburb of Tokyo, and in Konstanz, a middle-size town in Southern Germany. There were no significant differences between the two samples with respect to children's age ( $M=59.8$ months, $S D=5.2$ ), birth order (about $30 \%$ had no sibling, $9 \%$ were the youngest sibling, $28 \%$ were in the middle, and $33 \%$ were the oldest sibling), and number of siblings (about $42 \%$ had one sibling, $28 \%$ had 2 or more). The majority of the Japanese and German mothers had about the same educational level (BA or Abitur) and the majority of mothers $(60 \%)$ were homemakers. The majority of the families were from middle-class socioeconomic background in both cultures.

\section{Procedure}

The study was carried out in the children's kindergartens. Discussions about the procedure with Japanese researchers and a pilot study with several Japanese and German girls and their mothers were carried out to ensure that the two experimental conditions evoke distress. Japanese children and mothers are more used to sitting and playing on the floor, whereas German dyads prefer to sit at a table. Since Japanese children felt more comfortable on the floor in the pilot study, we adopted this cultural difference in order to ensure the equivalence of the procedures.

The girls were observed at two different time-points under two conditions that were designed to induce a negative emotion (distress): (a) At the first meeting (self-focused condition) the children had to manage an unsolvable task and experienced a disappointment on account of failure. (b) Several days later (3 to 5 days), the children were observed in an other-focused condition. By becoming involved in an interaction with a playmate, the child witnessed the distress of a playmate whose toy was accidentally destroyed. All sequences were videotaped for later analysis.

Self-focused condition. The mother was present in the condition. A trained young German and Japanese female student (about 18 years of age) served as experimenter and playmate. After a warming-up period between the mother and her daughter, the experimenter asked the child to make a replication of a painting within a limited time. Due to the time restriction, the child was not able to complete this task. The experimenter handed the necessary materials to the child and put a large hourglass on the table. After turning the hourglass, she excused herself and left the 
room. When the hourglass had run out (after 4 minutes), a stranger entered the room and said: "The time is over, I am sorry. I have to take the picture away". He took the uncompleted picture and left the room. Mother and child were left alone for about 2 minutes. Then the experimenter came back, praising the picture and the child for doing well. The child got her picture back and was allowed to take it home with her. At the end of this situation the experimenter played alone with the child for about 30 minutes.

Other-focused condition. In the second condition the mother was not present since the child should focus on the interaction with the experimenter. She started playing with the child in a warm-up setting for about 15 minutes. Then she introduced two balloons, gave one to the child and asked her to play together with the balloons. She mentioned that these balloons were the only ones left. During the play she repeated several times how much she liked her balloon and took care to ensure the child also enjoyed playing with her own balloon. At a suitable moment, the playmate secretly popped her balloon, and then displayed deep sadness. After about two minutes, she ended her sad expression and suggested that she will probably get another balloon to play with later. The sequence ended with the playmate and child playing together. The experimenter reassured the child that she will get another balloon soon in order to leave the child in a relaxed emotional state.

These two conditions were not counterbalanced because it was more important that the child became familiar with the playmate when participating in the other-focused condition.

\section{Variables}

Mothers' sensitivity. The categories to rate mother's interaction behaviour with her daughter were derived from the theoretical conceptualization of Roberts and Strayer (1987). Mothers' sensitivity was coded before and after the distress induction. In both situations, relevant aspects of sensitivity were observed.

Mothers' task-related sensitivity (before distress induction). The mother reacted to her daughter's emotions as well as to her daughter's task-oriented behaviour. Four sensitivity scales were used for coding. We differentiated between reactions to the child's emotional reactions vs. to the task as well as between responsiveness (promptness) vs. supportive behaviour of the mother.

Low responsiveness to the child's emotional reactions means that the mother does not go along with her child's emotional reactions, she seems to be unaffected; high responsiveness means that the mother reacts to the emotion of the child promptly, or smiles at the child as a kind of 
encouragement. Low task-oriented responsiveness means that the mother does not react promptly to the child's signals. High task-oriented responsiveness means that the mother reacts in a prompt way, e.g., answering questions. Each scale ranged from $1=$ low to $6=$ high .

Low supportive behaviour to the child's emotional reactions was rated when the mother commented on her child's emotional reactions in a harsh way or an aggressive voice; high supportive behaviour was rated when she commented in a soft and tender voice and when she tried to comfort or distract the child. Low task-oriented supportive behaviour was rated when the mother criticized the child's progress in the task in a devaluing way. High task-oriented supportive behaviour was rated when the mother communicated about the task by giving suggestions or asking whether she should help or when she encouraged the child even when the child made mistakes. These four measures of sensitivity were highly correlated and revealed high consistency for both cultural groups (Japanese mothers: Cronbach's $\alpha=.78$. German mothers: Cronbach's $\alpha=.93$ ). The mean value across these four ratings was computed and used for further analyses.

Mothers' distress-related sensitivity (after distress induction). The mothers were only confronted with the negative emotions of their children, as no task requirement was included. Therefore, only the two emotionrelated scales - responsiveness and supportive behaviour to child's emotional reactions - were rated here. The two measures in the disappointment situation were also highly correlated, Japanese mothers: $r(18)=.79$, $p<.001$; German mothers: $r(28)=.79, p<.001$. We computed the mean value of these two ratings for further data analyses.

Children's distress expression. Intensity of self-focused distress was coded on a 6-point scale from 0 (no negative expression) to 5 (strong negative expression) at four different time-points in the mother-child interaction: (1) beginning of the task; (2) shortly before; and (3) shortly after the distress induction; as well as (4) at the end of the situation. Each rating referred to a 10 second sequence. Time-point 1 (baseline) was coded after the experimenter left the room. Time-point 2 was coded about 30 seconds before the stranger entered the room (about 3 minutes later). Time-point 3 was rated 10 seconds after the stranger left (about 1 minute after time-point 2) and time-point 4 was coded just before the experimenter came back (about 2 minutes after time-point 3). In line with the respective emotion literature, characteristics of mimic, gestures, and posture were specified for the coding scheme (e.g., Eisenberg et al., 1988; Ekman \& Friesen, 1984).

Intensity of other-focused distress. Children's expression of other-focused distress was rated on a 6-point scale from 0 (no distress at all) to 5 (high distress) at three different time points: Time-point 1 (baseline) was coded one 
minute before the sad event, time-point 2 shortly after the sad event (about 10 seconds), and time-point 3 about two minutes later (shortly before the playmate finished her sad state). Children were rated as distressed when they showed tension in mimic, gesture, or posture according to the criteria developed by Eisenberg et al. (1988). Each rating referred to a 10 second sequence.

Course of emotional reaction is defined as the change (increase, maintenance, or decrease) of the intensity of distress expression across the four time-points in the self-focused condition and across the three timepoints in the other-focused condition.

\section{Interrater reliability}

All ratings were done by natives from the respective culture in order to reduce any cultural bias. Raters were coding blind to hypotheses. A second rating for half of the samples was done by a non-native for cross-validation. The Japanese data was transcribed from the videotapes and translated into German in order for a German rater to code the mother-child dyads $(50 \%$ of the sample). For the German data, no translation was necessary because the Japanese coder was able to read and speak German fluently. The mean correlations for interrater reliabilities for the subscales of mothers' sensitivity were $r(14)=.77, p<.001$ in Germany (range: .72 to .82 ) and $r(9)=.78, p<.01$ (range: .60 to .90 ) for Japan. The interrater reliabilities for the strength of girls' negative emotional expression were $r(14)=.76$, $p<.001$ (range: .60 to .92 ) in Germany and $r(9)=.83 . p<.01$ (range: .75 to .94) in Japan. Furthermore, significance of weighted Cohen's kappa was checked in order to control for systematic cultural bias of the two raters for both groups together. The mean kappa for sensitivity subscales was $\kappa=.49$, $p<.001$ (range: .40 to .62 ) and for the strength of girls' negative emotional expressions $\kappa=.57, p<.001$ (range: .40 to .78). The values showed satisfying interrater agreement. ${ }^{2}$

\section{Data analysis}

For analysing the course of emotional reaction, i.e., the change of girls' negative emotional expressions at the different time-points in both conditions, we used each time-point as an independent variable and computed an ANOVA model by nesting subjects into culture. This nested model leads to the

\footnotetext{
${ }^{2}$ When the number of ratings is small, Cohen's kappa values get low if one element of the diagonal is not represented or if there are only small deviations. Since only 11 ratings in the Japanese sample and 16 ratings in the German sample were available for testing interrater agreement, lower kappa values can be expected. Nevertheless, all kappas were significant and the agreement was beyond chance level.
} 
same effects as the MANOVA procedure. The advantage of this model consists in the possibility to calculate Least Square Means as post hoc tests for all combinations directly. The analyses were computed with SAS.

In order to analyse the effects of culture and mothers' sensitivity on girls' distress expression we applied two-steps regression analyses. In a first step, we used the intensity of distress expression of the earlier time-point as predictor of the later time-point. The residuals of this regression analysis represent the changes of the distress between the two time-points. By this, interindividual differences of baseline expressions are controlled. These residuals were used in a second step for regression with cultural group and maternal sensitivity as predictor variables.

\section{RESULTS}

\section{Successful induction of negative emotional reactions}

For the self-focused condition, a 2 (Culture) $\times 4$ (Time-Points) ANOVA $(2 \times 3$ ANOVA for the other-focused condition) with subjects as nested

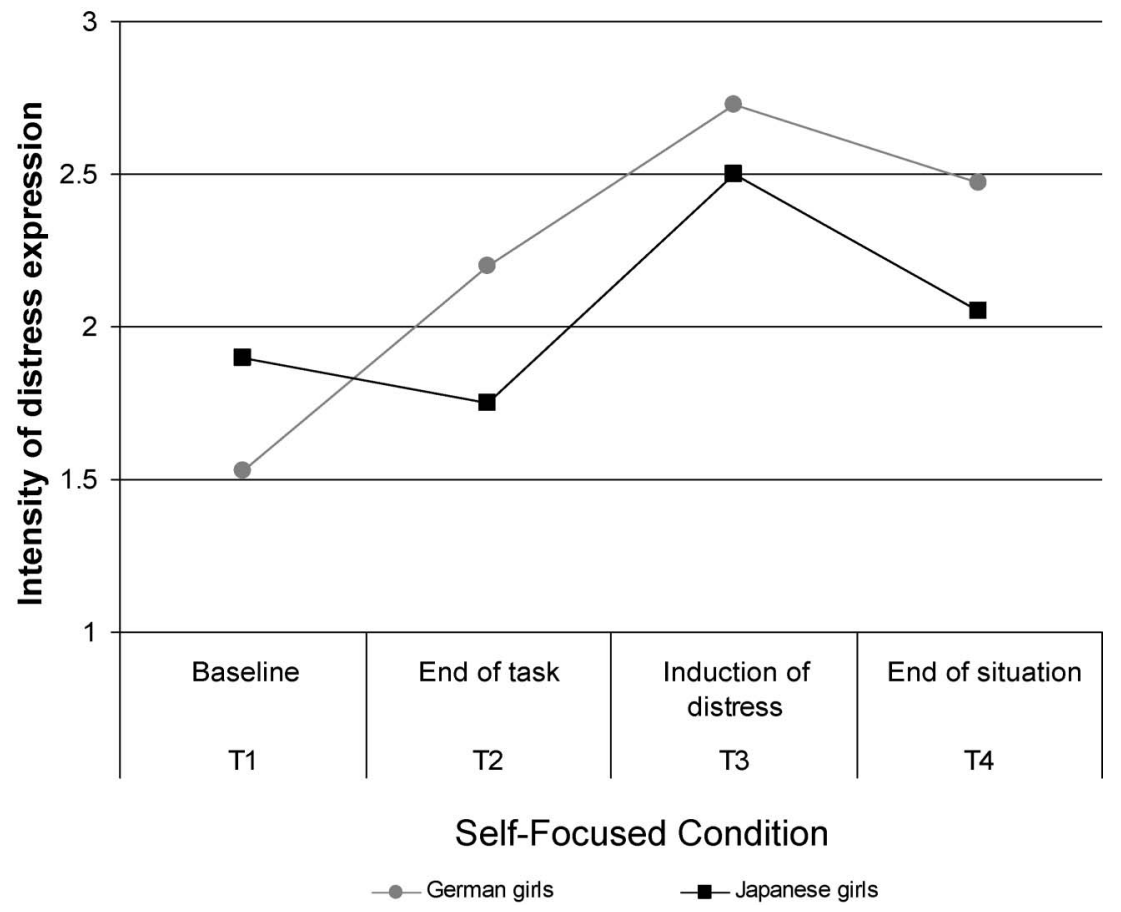

Figure 1. Intensity of distress expression in the self-focused condition. 


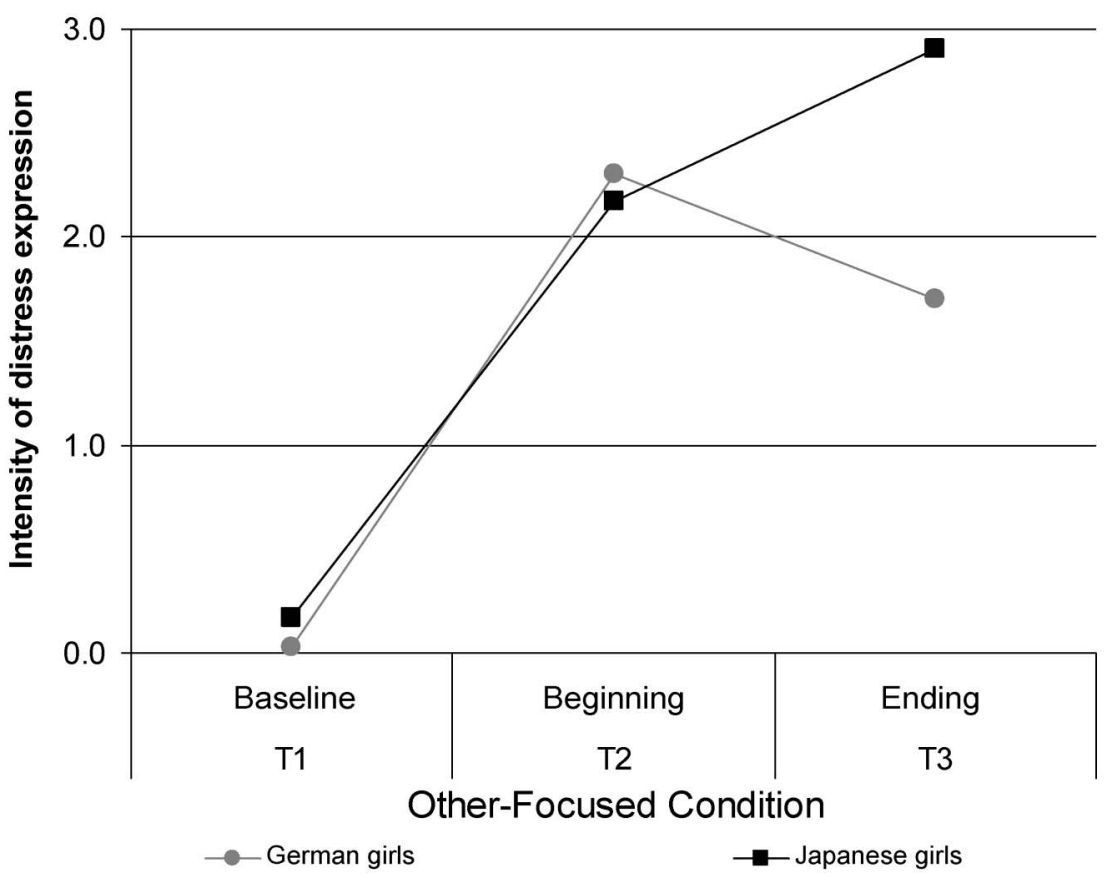

Figure 2. Intensity of distress expression in the other-focused condition.

factor within Culture were computed. The overall model was significant in both conditions, self-focused condition: $F(55,144)=3.97, p<.001$; $R^{2}=.60 ;$ other-focused condition, $F(56,102)=3.98, p<.001 ; R^{2}=.69$. Post hoc tests (Least Square Means; LSM) indicated that the difference of the distress expression from the baseline to the induction time-point was significant for both cultural groups in the self-focused condition (T1 compared with T3), $L S M=6.50, p<.001$ (see Figure 1) as well as in the other-focused condition (T1 compared with T2), $L S M=9.49, p<.001$ (see Figure 2). Neither cultural group differed in the baseline of the self-focused condition, $L S M=1.75, n s$, nor in the baseline of the other-focused condition, $L S M=0.44$, ns. These results indicate the successful induction of distress in both conditions for both cultural groups.

\section{Cultural differences in children's emotional expression and emotion regulation}

Self-focused condition (hypotheses 1 and 2). As mentioned above, the overall model for the ANOVA was significant. The intensity of children's 
distress expressions during the self-focused condition varied across the four time-points, $F(3,48)=15.55, p<.001$. This main effect was further qualified by a significant interaction effect between Culture and TimePoints, $F(3,48)=3.74, p<.01$ (see Table 1 and Figure 1). For the German girls, additional post hoc tests indicated a significant increase of distress expressions during the task (from T1 to T2), $L S M=3.80$, $p<.001$. The distress increased significantly after the distress induction (T3) compared to the end of the task situation (T2), $L S M=3.04, p<.01$. Distress expression decreased across the induction period (T4 compared to T3), although not significantly, $L S M=1.52$, ns. At the end of the condition (T4), the distress expression of the German girls was similar to the level at the end of the task situation (T2), $L S M=1.52, n s$, and still significantly higher than at the beginning of the condition (T1), $L S M=5.33, p<.001$.

In contrast, Japanese girls did not show an increase of distress expression during the task (from T1 to T2), $L S M=0.70, n s$. They showed a significant increase from the end of the task (T2) to the distress induction (T3), $L S M=2.10, p<.05$. Furthermore, Japanese girls showed significant decrease at the end (T4), $L S M=2.10, p<.05$. The intensity of their distress expression was similar to the beginning of the task (T1), $L S M=0.70, n s$.

Direct comparison of each time point between the two cultural groups showed that significant differences occurred at the end of the task (T2), $L S M=2.30, p<.05$, and at the end of the condition (T4), $L S M=2.13$, $p<.05$. In both cases, the expression of German girls' distress was stronger. No difference occurred at the beginning of the disappointment (T3), $L S M=1.19, n s$. These results confirm hypothesis 2 but we have to reject hypothesis 1 .

TABLE 1

Sequence of children's distress expression in self-focused condition

\begin{tabular}{|c|c|c|c|c|c|c|c|c|}
\hline & \multicolumn{8}{|c|}{ Intensity of girls' distress expressions } \\
\hline & \multicolumn{2}{|c|}{$\begin{array}{c}T 1 \\
\text { Baseline }\end{array}$} & \multicolumn{2}{|c|}{$\begin{array}{c}T 2 \\
\text { End of task }\end{array}$} & \multicolumn{2}{|c|}{$\begin{array}{c}\text { T3 } \\
\text { Induction } \\
\text { of distress }\end{array}$} & \multicolumn{2}{|c|}{$\begin{array}{c}\text { T4 } \\
\text { End of } \\
\text { situation }\end{array}$} \\
\hline & $M$ & $S D$ & $M$ & $S D$ & $M$ & $S D$ & $M$ & $S D$ \\
\hline $\begin{array}{l}\text { Germany }(N=30) \\
\operatorname{Japan}(N=20)\end{array}$ & $\begin{array}{l}1.53^{\mathrm{e}} \\
1.90^{\text {cde }}\end{array}$ & $\begin{array}{l}0.57 \\
0.85\end{array}$ & $\begin{array}{l}2.20^{\mathrm{bc}} \\
1.75^{\mathrm{de}}\end{array}$ & $\begin{array}{l}0.71 \\
0.85\end{array}$ & $\begin{array}{l}2.73^{\mathrm{a}} \\
2.50^{\mathrm{ab}}\end{array}$ & $\begin{array}{l}1.01 \\
0.89\end{array}$ & $\begin{array}{l}2.47^{\mathrm{ab}} \\
2.05^{\mathrm{cd}}\end{array}$ & $\begin{array}{l}0.90 \\
0.89\end{array}$ \\
\hline
\end{tabular}

Note: Means with the same superscript letters are not significantly different from each other. Scale: $0=$ no negative expression, $5=$ very strong negative expression. 
Other-focused condition (hypotheses 3 and 4). The overall model for the ANOVA was significant (see above). The intensity of children's distress expressions during the interaction with the playmate varied across Cultures, $F(1,51)=4.97, p<.05$, and the three Time-Points, $F(2,50)=62.07$, $p<.001$. Both effects were further qualified by a significant interaction effect between Culture and Time-Point, $F(2,50)=4.97, p<.01$ (see Table 2 and Figure 2). The significant increase from the baseline to the induced event has already been mentioned above. Post hoc tests indicated a significant cultural difference for the change of distress expression during the other-focused condition. German girls showed a significant decrease from T2 to T3, $L S M=2.03, p<.05$, whereas Japanese girls showed a significant increase, $L S M=2.19, p<.05$. This result is in line with hypothesis 4 . Hypothesis 3 has to be rejected as both groups of girls showed similar strength of distress expressions at the time-point of induction (T2) (Japanese: $M=2.17, S D=1.44$; German girls: $M=2.30, S D=1.49$ ), $L S M=0.39, n s$. While the strength of expression did not differ, the German girls displayed significant lower distress at the end of this situation $(M=1.70, \quad S D=1.60)$ compared to the Japanese girls $(M=2.91$, $S D=1.62), L S M=2.19, p<.05$.

\section{Cultural comparisons of mothers' sensitivity}

Significant differences in the levels of sensitivity displayed by German and Japanese mothers were found in both situations: Japanese mothers' taskrelated sensitivity $(M=5.09, S D=0.60)$ was significantly higher than German mothers' sensitivity $(M=3.95, \quad S D=1.50), \quad t(41.1)=-3.72$, $p<.01$, as well as their distress-related sensitivity (Japanese mothers: $M=5.13, S D=0.87$; German mothers: $M=4.25, S D=1.42), t(47.7)=$ $-2.69, p<.01$. Both measures of sensitivity were significantly positively correlated in the German sample, $r(28)=.49, p<.001$, while there was no

TABLE 2

Sequence of children's distress expression in other-focused condition

\begin{tabular}{|c|c|c|c|c|c|c|}
\hline & \multicolumn{6}{|c|}{ Intensity of girls' distress expressions } \\
\hline & \multicolumn{2}{|c|}{$\begin{array}{c}\text { T1 } \\
\text { Baseline }\end{array}$} & \multicolumn{2}{|c|}{$\begin{array}{c}\text { T2 } \\
\text { Beginning }\end{array}$} & \multicolumn{2}{|c|}{$\begin{array}{l}\text { T3 } \\
\text { End }\end{array}$} \\
\hline & $M$ & $S D$ & $M$ & $S D$ & $M$ & $S D$ \\
\hline Germany $(N=30)$ & $0.03^{\mathrm{a}}$ & 0.18 & $2.30^{\mathrm{c}}$ & 1.49 & $1.70^{\mathrm{b}}$ & 1.60 \\
\hline Japan $(N=20)$ & $0.17^{\mathrm{a}}$ & 0.39 & $2.17^{\mathrm{c}}$ & 1.44 & $2.91^{\mathrm{d}}$ & 1.62 \\
\hline
\end{tabular}

Note: Means with the same superscript letters are not significantly different from each other. Scale: $0=$ no negative expression, $5=$ very strong negative expression. 
correlation in the Japanese sample, $r(18)=.09$, ns. However, the difference between the correlation coefficients in both cultures did not reach significance, $z=1.42$, ns. Since the two sensitivity measures were not intercorrelated for the Japanese mothers, we kept the task- and distressrelated sensitivity measures separate for the following analyses.

\section{Effects of mothers' sensitivity on children's emotions in the self-focused condition (hypothesis 5)}

Culture and mothers' sensitivity during task and distress were used as predictors for the daughters' change of distress expression. The three predictors were centred.

Mothers' sensitivity was not predictive for girls' change of distress expression directly after the induction, $F(3,48)<1.0, n s$, in both models. There were also no effects of mothers' task-related sensitivity on girls' change of distress expression at the end of the self-focused condition, $F(3$, $46)=0.86, n s$. However, the regression model with mothers' distress-related sensitivity was significant, $F(3,46)=3.41, p<.05, R^{2}=.18$. The effects of mothers' sensitivity on girls' strength of distress expression differed significantly between the two cultural groups (Culture $\times$ Sensitivity: $\beta=.45, t=2.01, p<.05)$. The more sensitive the German mothers, the stronger was the increase of the girls' distress expression in this situation, $\beta=.27, t=2.71, p<.01$, whereas the relation for Japanese dyads pointed into opposite direction, $\beta=-.18, t=0.87$, ns. This culture-specific pattern confirms hypothesis 5 .

\section{Effects of mothers' sensitivity on children's emotions in the other-focused condition}

Maternal sensitivity had no impact on the girls' spontaneous distress expressions (comparing changes between $\mathrm{T} 1$ and T2). Neither overall regression model was significant, task-related sensitivity: $F(3,46)=1.43, n s$; distress-related sensitivity: $F(3,46)=0.67, n s$.

The regression analyses for the change of distress reaction after the distress event showed that the overall model with maternal distress-related sensitivity was predictive, $F(3,46)=8.16, p<.001$. The more sensitively the mother reacted in the self-focused condition, the more the girl's distress expressions increased over time in the other-focused condition, $\beta=-1.08$, $t=2.98, p<.01$. This effect was stronger for Japanese dyads $(\beta=1.07$, $t=3.04, p<.01)$ than for the German dyads $(\beta=.44, t=2.52, p=.05)$, but the interaction effect was only marginally significant, $\beta=.64, t=1.65$, $p<.10$. These results lead to the rejection of hypothesis 5 although the results point in the expected direction. 


\section{DISCUSSION}

This study analysed preschool girls' distress reactions by taking cultural context (and related values of independence and interdependence), situational contexts (self-focused vs. other-focused situations), and maternal sensitivity into account. In order to maximize the theoretical and empirical implications of this investigation, we selected two cultural contexts, which differ from each other in theoretically relevant aspects, and studied the distress expression in two conditions that were hypothesized to evoke inverse behaviour patterns for the two cultural groups. The hypotheses were derived from culture-specific norms about emotion as well as empirical studies about different socialization practices in Germany and Japan. These different norms and socialization conditions fit with the general cultural models of independence and interdependence (Heine, 2001; Markus \& Kitayama, 1991; Rothbaum et al., 2000).

Japanese and German girls did not show the expected culture-specific situational differences regarding the spontaneous distress expressions. The strength of the expression directly after the induction of self-focused distress as well as after the induction of other-focused distress was similar for both groups. Therefore, hypotheses 1 and 3 were rejected. Preschoolers might not yet be able to apply culturally approved display rules to the spontaneous expression of distress. Since stronger control of negative emotional expression occurs in Japanese adults (e.g., Ekman, 1972), children may learn and internalize this culturally valued behaviour later. The spontaneous distress expression of the 5-year-old girls does not seem to be affected (yet) by culture-specific socialization. This argument is supported by our finding that none of the two sensitivity measures was related to the strength of spontaneous distress reaction.

In contrast, Japanese and German girls showed the expected culturespecific situational differences regarding the maintenance of the distress expression. These results confirm hypotheses 2 and 4 . In the self-focused condition, German girls sustained the distress expression, whereas Japanese girls decreased their distress expression to baseline levels at the end of the situation. The longer maintenance of German girls' distress fits with the value of authentic self expression in a context favouring independence (Kitayama, 2001; Kitayama \& Markus, 1994). In Japan, a cultural context favouring interdependence, such expression is rather avoided. If the emotional expression is evaluated as inadequate, cultural members express it less and do not focus on appraisals that evoke such reactions (e.g., Eid \& Diener, 2001).

The emotional reactions in the other-focused condition also yielded culture-specific differences in the expected way: Japanese girls sustained their distress expression whereas German girls decreased their expression until the 
end of the interaction. On the one hand, this result speaks for higher involvement of Japanese children with the playmate and therefore for more concern for her failure. On the other hand, a confounding factor may come into play that was not controlled in our design: Presumably, the absence of their mothers did not allow the Japanese girls to reassure themselves by reference to their mothers. This experience of facing a difficult situation by themselves (separate from their mothers) may have contributed to an increase in their negative socially engaged emotion. German girls, however, have presumably profited from culture-specific socialization conditions demanding less reliance on the caretaker when regulating emotions. According to these results it seems that cultural differences refer to the maintenance and change of distress reactions rather than to the spontaneous display of negative emotions. It remains a question for the future whether this pattern rather applies to preschool children or to older age groups as well.

Cultural differences in maternal sensitivity occurred. Japanese mothers were more sensitive than German mothers in both situations. Japanese mothers' sensitivity varied according to the situational context while German mothers' sensitivity was not affected by the situation. Maternal sensitivity may thus be viewed as a "state" phenomenon for Japanese mothers and as a "trait" for German mothers. However, the variability in sensitivity for the Japanese mothers might be a methodical artefact: the high means of sensitivity for the Japanese mothers and the restricted variance may be a reason for not finding interindividual stability for this group.

The context in which sensitivity is observed played a crucial role for both cultural groups. Culture-specific effects of maternal sensitivity on daughters' distress were solely found with regard to distress-related sensitivity. Thus, hypothesis 5 was only partly confirmed. The more sensitive the German mothers were, the less their daughters' distress decreased during the selffocused condition. The reverse effects occurred for Japanese dyads. It seems that German mothers' sensitivity reinforces the distress expressions of the child thus increasing the child's expression of distress. The German mothers may have evaluated the situation differently: they have attributed the child's failure to the experimenter. Furthermore, German mothers presumably interpret their daughters' strong negative expressions as a valid indicator of the child's authenticity, open expression, and self-reliance, and thereby also as an indicator for the positive quality of the mother-child relationship. In Japan, an important developmental goal is to achieve maturity (Trommsdorff \& Rothbaum, 2008). Here, a different evaluation of emotional expression prevails and influences the mothers' reaction to their daughters' negative emotions.

Apparently, the mothers' distress-related sensitivity promotes their children's culturally appropriate maintenance and change of distress 
expression. The more sensitivity the mother displayed in the self-focused condition, the more children sustained the distress expression in the otherfocused condition; and Japanese girls even showed an increase of their distress expression, although the cultural difference was only marginally significant. Culture-specific processes of emotional development may be influential here. Japanese girls of highly sensitive mothers may have internalized the cultural values of interdependence more and express concern for the other person's failure more strongly. This interpretation is in line with another study demonstrating greater distress in children from cultural contexts where interdependence is highly valued observed in an otherfocused condition (Trommsdorff et al., 2007). Alternatively, their stronger interdependence may also lead to a higher need of their mother's support in emotion evoking situations as already mentioned above. However, this interpretation remains speculative since we could not systematically vary the mother's presence across situations due to constraints in the experimental design.

\section{Limitations and future directions}

The generalizability of our study is limited due to the small sample size. There is a lack of power especially in the Japanese sample. Therefore, some significant effects may not have occurred due to the small number of participants. Furthermore, we only included mother-daughter dyads in the sample. It remains a future task to explore gender-related differences of distress reactions and gender-specific emotion socialization and its variation across different cultures.

In contrast to many studies on emotion, we avoided sole reliance on verbal responses to assess emotions and socialization conditions and instead collected data by behavioural observation. Our interpretation of cultural differences refers to different cultural norms and different socialization as reported in the literature. We applied the model of self as a heuristic framework. Since knowledge about children's emotional development in different cultures is still very limited and the dichotomous model of self cannot reflect the range of intracultural variations of individual values, beliefs, and related behaviour, we did not intend to test the heuristic framework in a strict sense. A more direct test of cultural characteristics should be done in the future, e.g., by empirically investigating mothers' child-rearing values, their beliefs on emotions and emotion development and values of mothers from different cultures.

Additionally, the relation between parenting and children's expression of emotions may be mediated by children's emotional reactivity (Eisenberg et al., 1998). Our study does not provide empirical evidence as to whether children's or mothers' behaviour reflected temperamental 
differences that may be differentially related to cultural heritage (e.g., Lewis, 1989).

The strengths of this study include its focus on girls' emotional responses and their socialization conditions in a Western and a non-Western culture, the variation of conditions for eliciting self- and other-focused distress, and the observational and laboratory assessment of mothers' and children's behaviour.

To conclude, the study confirms that cultures have different emphases on other-directedness and self-directedness of emotional reactions (ZahnWaxler et al., 1996) and shows a differentiated pattern regarding commonalities and differences in children's distress expression. The main contribution of this study consists in demonstrating that the distress expression of 5-year-old Japanese and German girls does not differ with regard to spontaneous expression, but culture-specifically expected patterns - in line with cultural values-occur with regard to the maintenance of the change of the expression over a short time period. Furthermore, mothers sensitivity toward their daughters' distress expression was related to the maintenance of the girls' expression, especially in the self-focused situation. Sensitive mothers in both cultures are more successful in promoting culturally valued ways of how their daughters changed the self-focused distress. The spontaneous distress expression was the same for Japanese and German children and it remains a question for future studies at what age and under which conditions cultural differences might appear.

Manuscript received 26 October 2007 Revised manuscript accepted 28 May 2008

First published online 10 June 2009

\section{REFERENCES}

Azuma, H. (1986). Why study child development in Japan? In H. Stevenson, H. Azuma, \& K. Hakuta (Eds.), Child development and education in Japan (pp. 3-12). New York: Freeman.

Bowlby, J. (1982). Attachment and loss: Vol. 1. Attachment (2nd ed.). New York: Basic Books. Bretherton, I., Golby, B., \& Cho, E. (1997). Attachment and the transmission of values. In J. E. Grusec \& L. Kuczynski (Eds.), Parenting and children's internalization of values: A handbook of contemporary theory (pp. 103-134). New York: Wiley.

Caudill, W., \& Weinstein, H. (1986). Maternal care and infant behavior in Japan and America. In T. S. Lebra \& W. P. Lebra (Eds.), Japanese culture and behavior (pp. 226-276). Honolulu, HI: University of Hawaii Press.

Chaplin, T. M., Cole, P. M., \& Zahn-Waxler, C. (2005). Parental socialization of emotion expression: Gender differences and relations to child adjustment. Emotion, 5, 80-88.

Cole, P. M., Tamang, B. L., \& Shrestha, S. (2006). Cultural variations in the socialization of young children's anger and shame. Child Development, 77, 1237-1251. 
Cole, P. M., \& Tan, P. Z. (2006). Capturing the culture in the cultural socialization of emotion. ISSBD Newsletter, 49, 5-7.

Doi, T. (1973). The anatomy of dependence. Tokyo: Kodansha.

Eid, M., \& Diener, E. (2001). Norms for experiencing emotions in different cultures: Interand intranational differences. Journal of Personality and Social Psychology, 81, 869885.

Eisenberg, N., Cumberland, A., \& Spinrad, T. L. (1998). Parental socialization of emotion. Psychological Inquiry, 9, 241-273.

Eisenberg, N., Fabes, R. A., \& Murphy, B. C. (1996). Parents' reactions to children's negative emotions: Relations to children's social competence and comforting behavior. Child Development, 67, 2227-2247.

Eisenberg, N., Schaller, M., Fabes, R. A., Bustamante, D., Mathy, R. M., Shell, R., et al. (1988). Differentiation of personal distress and sympathy in children and adults. Developmental Psychology, 24, 766-775.

Ekman, P. (1972). Universals and cultural differences in facial expressions of emotion. In J. Cole (Ed.), Nebraska symposium of motivation (Vol. 19, pp. 207-283). Lincoln, NE: University of Nebraska Press.

Ekman, P., \& Friesen, W. (1984). Unmasking the face: A guide to recognizing emotions from facial clues. Palo Alto, CA: Consulting Psychologists Press.

Fivush, R. (1998). Gendered narratives: Elaboration, structure, and emotion in parent-child reminiscing across the preschool years. In C. P. Thompson, D. J. Herrmann, D. Bruce, J. D. Read, \& D. G. Payne (Eds.), Autobiographical memory: Theoretical and applied perspectives (pp. 79-103). Mahwah, NJ: Lawrence Erlbaum Associates, Inc.

Fogel, A. (1993). Development through relationships: Origins of communication, self, and culture. Chicago: University of Chicago Press.

Friedlmeier, W., \& Matsumoto, D. (2007). Emotion und Emotionsregulation im Kulturvergleich [Emotion and emotion regulation in cross-cultural perspective]. In G. Trommsdorff \& H.-J. Kornadt (Eds.), Kulturvergleichende Psychologie, Band 2. Enzyklopädie der Psychologie, Serie VII, Themenbereich C "Theorie und Forschung" (pp. 219-281). Göttingen, Germany: Hogrefe Verlag.

Greenfield, P., Keller, H., Fuligni, A., \& Maynard, A. (2003). Cultural pathways through universal development. Annual Review of Psychology, 54, 461-490.

Grusec, J. E., \& Davidov, M. (2007). Socialization in the family: The roles of parents. In J. E. Grusec \& P. D. Hastings (Eds.), Handbook of socialization (pp. 284-308). New York: Guilford Press.

Heine, S. J. (2001). Self as cultural product. An examination of East Asian and North American selves. Journal of Personality, 69, 881-906.

Holodynski, M., \& Friedlmeier, W. (2006). Development of emotions and emotion regulation. New York: Springer.

Kitayama, S. (2001). Culture and emotion. In N. J. Smelser \& P. B. Baltes (Eds.), International encyclopedia of the social and behavioral sciences (pp. 3134-3139). Oxford, UK: Elsevier.

Kitayama, S., \& Markus, H. R. (Eds.). (1994). Emotion and culture: Empirical studies of mutual influence. Washington, DC: American Psychological Association.

Kliewer, W., Fearnow, M. D., \& Miller, P. A. (1996). Coping socialization in middle childhood: Tests of maternal and paternal influences. Child Development, 67, 2339-2357.

Kochanska, G. (2001). Emotional development in children with different attachment histories: The first three years. Child Development, 72, 474-490.

Lebra, T. S. (1994). Mother and child in Japanese socialization: A Japan-U. S. comparison. In P. M. Greenfield \& R. R. Cooking (Eds.), Cross-cultural roots of minority development (pp. 259-274). Hillsdale, NJ: Lawrence Erlbaum Associates, Inc. 
Lewis, M. (1989). Culture and biology: The role of temperament. In P. Zelazo \& R. Barr (Eds.), Challenges to developmental paradigms (pp. 203-223). Hillsdale, NJ: Lawrence Erlbaum Associates, Inc.

Markus, H. R., \& Kitayama, S. (1991). Culture and the self: Implications for cognition, emotion, and motivation. New York: Tavistock.

Mesquita, B., \& Frijda, N. H. (1992). Cultural variations in emotions: A review. Psychological Bulletin, 112, 197-204.

Raver, C. C. (2004). Placing emotional self-regulation in sociocultural and socioeconomic contexts. Child Development, 75, 346-353.

Roberts, W., \& Strayer, J. (1987). Parents' responses to the emotional distress of their children: Relations with children's competence. Developmental Psychology, 23, 415-422.

Rothbaum, F., \& Morelli, G. (2005). Attachment and culture: Bridging relativism and universalism. In W. Friedlmeier, P. Chakkarath, \& B. Schwarz (Eds.), Culture and human development. The importance of cross-cultural research for the social sciences (pp. 99-123). Hove, UK: Psychology Press.

Rothbaum, F., Pott, M., Azuma, H., Miyake, K., \& Weisz, J. (2000). The development of close relationships in Japan and the United States: Paths of symbiotic harmony and generative tension. Child Development, 71, 1121-1142.

Rothbaum, F., \& Trommsdorff, G. (2007). Do roots and wings complement or oppose one another? The socialization of relatedness and autonomy in cultural context. In J. E. Grusec \& P. Hastings (Eds.), The handbook of socialization (pp. 461-489). New York: Guilford Press.

Saarni, C. (1998). Issues of cultural meaningfulness in emotional development [Special Issue: Social and Emotional Development: A Cross-Cultural Perspective]. Developmental Psychology, 34, 647-652.

Trommsdorff, G. (2006). Development of emotions as organized by culture. ISSBD Newsletter, $49,1-4$.

Trommsdorff, G., \& Friedlmeier, W. (1993). Control behavior and responsiveness in Japanese and German mothers. Early Development and Parenting, 2, 65-78.

Trommsdorff, G., Friedlmeier, W., \& Mayer, B. (2007). Sympathy, distress, and prosocial behavior of preschool children in four cultures. International Journal of Behavioural Development, 31, 284-293.

Trommsdorff, G., \& Rothbaum, F. (2008). Development of emotion-regulation as part of selfregulation in cultural context. In S. Ismer, S. Jung, S. Kronast, C. v. Scheve, \& M. Vandekerckhove (Eds.), Regulating emotions: Social necessity and biological inheritance (pp. 85-120). London: Blackwell.

Yamaguchi, S., \& Ariizumi, Y. (2006). Close interpersonal relationships among Japanese: Amae as distinguished from attachment and dependence. In U. Kim, K.-S. Yang, \& K.-K. Hwang (Eds.), Indigenous and cultural psychology: Understanding people in context (pp. 163-175). New York: Springer.

Zahn-Waxler, C., Friedman, R. J., Cole, P. M., Mizuta, I., \& Hiruma, N. (1996). Japanese and United States preschool children's responses to conflict and distress. Child Development, 67, 2462-2477. 